\title{
Control of a Three-phase Off-Grid Inverter for Photovoltaic Systems Applications
}

\author{
Ali M A Almaktoof, Abdulsslam M Ashoor Shaouf, Abdulbaset A Salem Wddan \\ Department of Electrical and Electronic, Faculty of Engineering, Sabratha University, Libya \\ DOI: https://doi.org/10.21467/proceedings.2.27 \\ * Corresponding author email: alialmaktoof@gmail.com
}

\begin{abstract}
This paper presented a model predictive control (MPC) strategy as used in photovoltaic (PV) systems applications to control a three-phase off-grid inverter. The PVs model was used in this study to investigate the system performance when power is supplied to a resistive-inductive load (RL-load).

The proposed strategy is to handle the output current for the three-phase, off-grid inverter with an RL-load. An assessment is given of the robustness of the control strategy under variable DC voltages, and as required for photovoltaic systems applications, by measuring the Total harmonic distortion (THD) and tracking behaviour of the reference currents; this was done for all DC voltage values. The system is tested as well with different sampling times to check the tracking behavior at designed values. The simulations and result analyses are carried out using MATLAB/Simulink to test the effectiveness and robustness of MPC for three-phase off-grid inverter with resistiveinductive load supplied by a PV system. The simulation results indicated that the proposed control algorithms achieved both high performance and a high degree of robustness in photovoltaic systems applications.
\end{abstract}

Keywords: Finite State-Model Predictive Control, three-phase off-grid inverter, photovoltaic systems.

\section{Introduction}

In recent years the use of renewable energy systems has become very important due to environmental concerns and the increased demand for energy [1, 2]. Renewable energy resources like solar energy can be used with maximum efficiency by utilizing appropriate power converters. As the availability of this energy resource is greatly uncertain, the power conversion system must rely on a suitable power converter and controller unit [3, 4]. The urge to increase the energy efficiency of all energy related systems in combination with the need to support emerging technologies like sustainable energy sources, promotes the development of highly efficient, high-power converters. Three-phase off-grid inverters are widely used in industrial applications and renewable energy systems $[2,5]$.

Model predictive control (MPC) for power converters has been researched since the early 1980s [5]. MPC requires a high number of calculations as compared to classic control methods,

(C) 2018 Copyright held by the author(s). Published by AIJR Publisher in Proceedings of First Conference for Engineering

Sciences and Technology (CEST-2018), September 25-27, 2018, vol. 1 .
This is an open access article under Creative Commons Attribution-NonCommercial 4.0 International (CC BY-NC 4.0)

license, which permits any non-commercial use, distribution, adaptation, and reproduction in any medium, as long as the

AijR original work is properly cited. ISBN: 978-81-936820-5-0 
Control of a Three-phase Off-Grid Inverter for Photovoltaic Systems Applications

but the fast microprocessors available today have made it possible to viably implement predictive control coupled with three-phase inverter with long prediction horizon [7]. Furthermore, MPC for power converters has distinct advantages when compared to the traditional pulse width modulation (PWM) methods [8].

Since power converters have a finite number of switching states, the MPC optimization problem can be easily formulated, simplified and reduced to the prediction of the system behaviour specifically for those possible switching states. This control method is known as a finite state-model predictive control (FS-MPC) approach. Many studies have been conducted into the successful application of FS-MPC schemes incorporated in three-phase inverters and drive applications [9-12].

The paper starts with an overview of the system description which presented in Section 2. This paper presents one of the simplest predictive control schemes, which is current control for a three-phase inverter. A simple model of the converter and the load are presented in section 3 and 4 respectively. The model predictive control of off-grid inverter is developed in Section 5. Results and discussions are presented next, followed by a conclusion in the last section of the paper.

\section{System Description Overview}

A three-phase off-grid inverter for the commonly renewable energy source available in Libya (solar energy) subject to model predictive control strategy is shown in Figure 1. Considering that the two switches in each inverter phase operate in a complementary mode in order to avoid short circuiting the DC source, the switching state of the power switches $S_{x}$, with $x=1$, $\ldots, 6$, can be represented by the switching signals $S_{a}, S_{b}$, and $S_{c}$ defined as follows:

$S_{a}=\left\{\begin{array}{l}1 \text { if } S_{1} \text { on and } S_{4} \text { off } \\ 0 \text { if } S_{1} \text { off and } S_{4} \text { on }\end{array}\right\}$

$S_{b}=\left\{\begin{array}{l}1 \text { if } S_{2} \text { on and } S_{5} \text { off } \\ 0 \text { if } S_{2} \text { off and } S_{5} \text { on }\end{array}\right\}$

$S_{c}=\left\{\begin{array}{l}1 \text { if } S_{3} \text { on and } S_{6} \text { off } \\ 0 \text { if } S_{3} \text { off and } S_{6} \text { on }\end{array}\right\}$

These switching signals define the value of the output voltages

$V_{a N}=S_{a} V_{d c}$

$V_{b N}=S_{b} V_{d c}$

$V_{c N}=S_{c} V_{d c}$

Where $V_{d c}$ is the DC source voltage. 
Considering all the possible combinations of the gating signals $S_{a}, S_{b}$, and $S_{c}$, eight switching states and consequently eight voltage vectors are obtained (see Figure 2). In Figure 2 note that $\mathrm{V}_{0}=\mathrm{V}_{7}$, resulting in a finite state of only seven different voltage vectors in the complex plane.

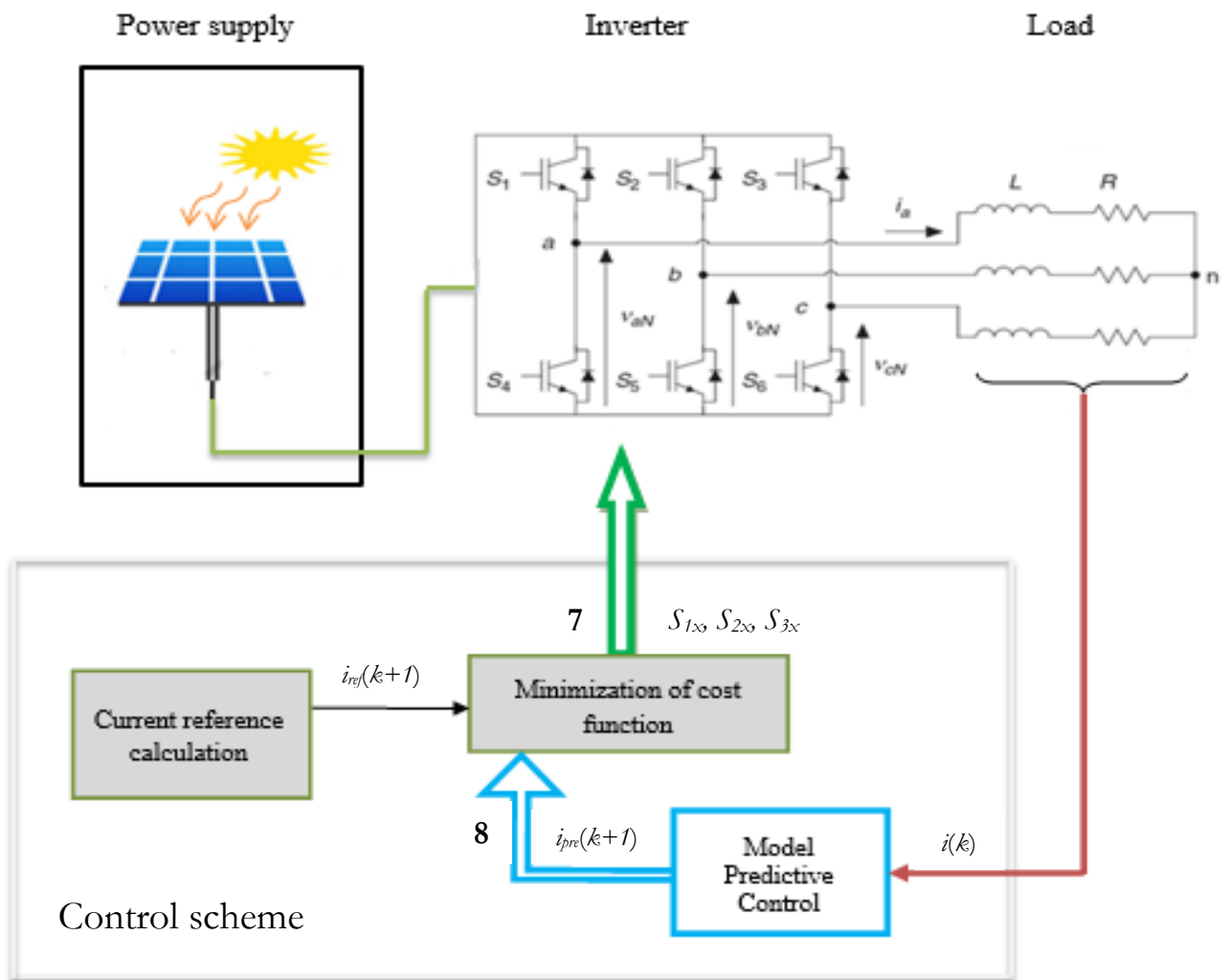

Figure 1: Inverter topology connected to the load and control block diagram

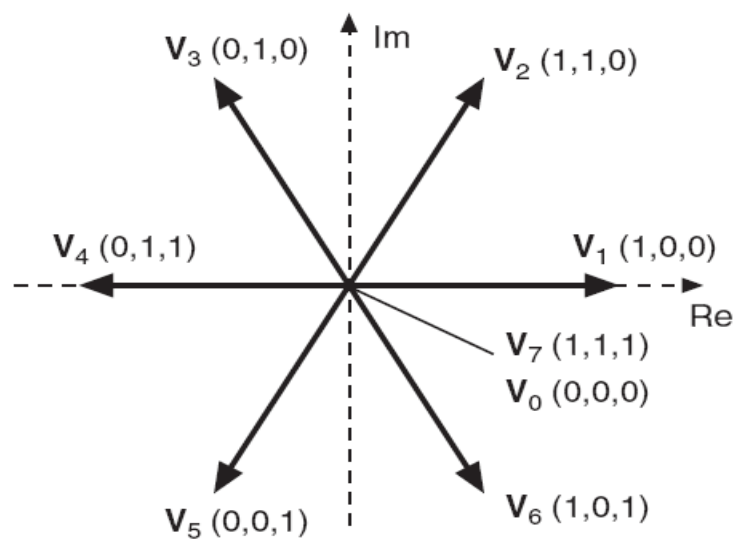

Figure 2: Voltage vectors in the complex plane. 
Control of a Three-phase Off-Grid Inverter for Photovoltaic Systems Applications

\section{Load Model}

The differential equation of the load current for the inverter is applied to obtain the continuous-time state space equations of the load for each phase, the load current dynamics can be described by the vector differential equation

$v_{D C}(t)=\mathrm{R}_{L} \cdot i(t)+\mathrm{L}_{L} \frac{d i}{d t}$

Where $\mathrm{v}$ is the voltage vector generated by the inverter, $i$ is the load current vector. The load current derivative $\frac{d i}{d t}$ is replaced by a forward Euler approximation [7]. That is, the derivative is approximated as follows:

$\frac{d i}{d t} \approx \frac{\mathrm{i}(k+1)-\mathrm{i}(k)}{T_{S}}$

Which is substituted in (7) to obtain an expression that allows prediction of the future load current at time $k+1$, for each one of the seven values of voltage vector $\mathrm{v}(k)$ generated by the inverter. This expression is

$\mathrm{i}^{\mathrm{p}}(k+1)=\left(1-\frac{R T_{s}}{L}\right) \mathrm{i}(k)+\frac{T_{S}}{L} \mathrm{v}(K)$

Using the Clarke transformation, Clarke transformation is defined as following,

$v \alpha=2 / 3(V a-0.5 V b-0.5 V c)$

$v \beta=2 / 3(0.5 \sqrt{3} V b-0.5 \sqrt{3} V c)$

Then, the discrete-time load model can be to:

$\left(\begin{array}{c}i_{\alpha}(k+1) \\ i_{\beta}(k+1)\end{array}\right)=\left(\begin{array}{cc}1-T_{S} \frac{R_{L}}{L_{L}} & 0 \\ 0 & 1-T_{S} \frac{R_{L}}{L_{L}}\end{array}\right)\left(\begin{array}{c}i_{\alpha}(k) \\ i_{\beta}(k)\end{array}\right)+\left(\begin{array}{cc}\frac{T_{S}}{L_{L}} & 0 \\ 0 & \frac{T_{S}}{L_{L}}\end{array}\right)\left(\begin{array}{c}v_{\alpha}(k) \\ v_{\beta}(k)\end{array}\right)$.

Equation (12) is used to predict the load current for each switching possibility.

\section{Cost Function}

The objective of the current control scheme is to minimize the error between the measured currents and the reference values. This requirement can be written in the form of a cost function $[7,8]$. The cost function $g$ is evaluated for each of the seven possible voltage vectors generated by this inverter to calculate the future value of the load current. The voltage vector that minimizes the cost function is selected and applied during the next sampling instant. The cost function is expressed in orthogonal coordinates and measures the error between the references and the predicted currents:

$g=\left|i_{\alpha}^{*}(k+1)-i_{\alpha}^{\mathrm{p}}(k+1)\right|+\left|i_{\beta}^{*}(k+1)-i_{\beta}^{\mathrm{p}}(k+1)\right|$ 


\section{$5 \quad$ Model Predictive Control of Off-Grid Inverter}

As presented early in Figure 1 a three-phase off-grid inverter for a PV system application subject to model predictive control strategy where $i_{r f}$ represents the reference current for the predictive control, $i(k)$ is the measured variable current at time, $k$, and $i_{p r e}(k+1)$ is the predicted current for $n$ allowed switching states at time, $(k+1)$. The errors between the reference and predicted values are obtained to minimize the cost function, and the switching state that minimizes the cost function, is chosen. The switching signals, $\mathrm{S}$, of the chosen state are then applied to the converter. To reduce the computational effort that arises from the switching possibilities ( 8 different switching possibilities for one prediction step), the switching state that delivers the best voltage vector among 7 voltage vectors is determined; this was illustrated in Figure 2. The optimal switching state, which is the one that minimizes the simple cost function, is selected and applied at the next sampling instance when the time is $(k+1)$. The block diagram of the different tasks performed by the predictive controller is shown earlier in Figure 1. In general, the control algorithm, can be summarized by the following steps:

(1) Measure the load currents and DC voltage.

(2) Initialize the value of the optimum cost function.

(3) For all permissible switching states, predict the load currents and capacitor voltages for the next sampling instant.

(4) Evaluate the cost function for each prediction.

(5) Select the optimal switching state that minimizes the cost function.

(6) Apply the new switching state.

\section{Results and Discussion}

The simulations and result analyses are carried out using MATLAB to test the effectiveness and robustness of FS-MPC for a three-phase, two-level off-grid inverter with resistiveinductive load supplied by a photovoltaic system as shown in Figure 1. Table 1 shows the parameters used for the simulation.

Table 1: Parameters used for the co-simulations

\begin{tabular}{|c|c|}
\hline Parameter & Value \\
\hline Load resistance, $R$ & $10 \Omega$ \\
\hline Load inductance, $L$ & $35 \mathrm{mH}$ \\
\hline DC voltage, $\boldsymbol{v}_{\boldsymbol{D C}}$ & $300 \mathrm{~V}$ \\
\hline Amplitude of the reference current, $\boldsymbol{i}_{\boldsymbol{r} \text { ef }}$ & $8 \mathrm{~A}$ \\
\hline Sampling time, $T \mathrm{~s}$ & $100 \mu \mathrm{s}$ \\
\hline
\end{tabular}

The control algorithm was evaluated with regard to two performance indicators: Firstly, the robustness and variability of control strategy under variable input DC voltage is done, and secondly, with different sampling time, the system is investigated.

Proceedings of First Conference for Engineering Sciences and Technology (CEST-2018), vol. 1 
Control of a Three-phase Off-Grid Inverter for Photovoltaic Systems Applications

\subsection{Control strategy robustness under variable DC voltages}

In this simulation the system is designed at a voltage value is $300 \mathrm{~V}$ at sampling time $\mathrm{Ts}=75$ $\mu$ s. Figure 3 shows the output current i_ $\alpha$, magnitude value of output current and output voltage $v_{-} \alpha$ by using Fast Fourier Transform (FFT) in MATLAB/SUMLINK.

To demonstrate the stability of the proposed control method under conditions of variable DC voltages; the system has been tested when the DC voltage was changed from 125 to $600 \mathrm{~V}$ with TS $=75 \mu$ s. Figure 4 shows the output currents for different values of DC voltages. It can be observed that the proposed control algorithm has the ability to follow sinusoidal reference currents despite substantially changing the DC voltage from the desired voltage except Figure 4(a). These results of the simulation are in Table 2.
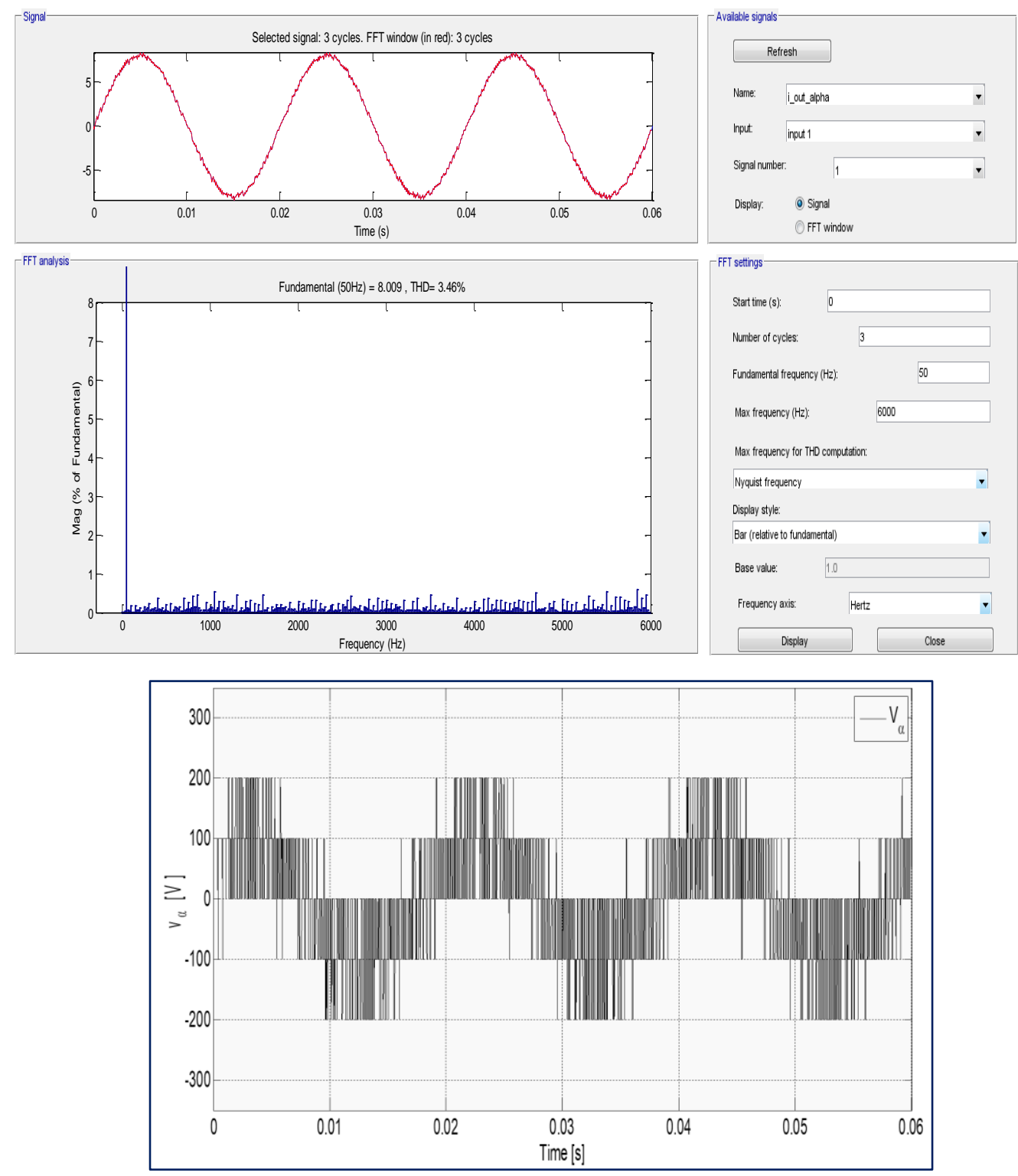

Figure 3: Output current and its magnitude value and output voltage at designed values. 
Almaktoof et al., CEST-2018, AIJR Proceedings 2, pp.223-232, 2018

Table 2: THD and output current for variable DC voltages

\begin{tabular}{|c|c|c|}
\hline DC-Link value, [ V ] & Fund. current at $50 \mathrm{~Hz},[\mathrm{~A}]$ & THD [\%] \\
\hline 125 & 6.096 & 7.76 \\
\hline 200 & 8.007 & 2.33 \\
\hline 220 & 8.015 & 2.66 \\
\hline 240 & 8.006 & 2.69 \\
\hline 260 & 7.978 & 2.95 \\
\hline 280 & 8.000 & 3.35 \\
\hline 320 & 7.971 & 3.46 \\
\hline 340 & 8.021 & 3.85 \\
\hline 360 & 7.981 & 4.14 \\
\hline 380 & 7.999 & 4.30 \\
\hline 400 & 7.969 & 4.66 \\
\hline 450 & 7.945 & 5.07 \\
\hline 500 & 8.008 & 5.71 \\
\hline 550 & 7.997 & 6.41 \\
\hline 600 & 7.961 & 6.64 \\
\hline
\end{tabular}

In Figure 4(a) is shown the output current of the DC voltage when it was set to $125 \mathrm{~V}$ and the THD was $7.76 \%$ and the fundamental current at $50 \mathrm{~Hz}$ is 6.096 . It is notable that the system was out of control at $125 \mathrm{~V}$ with high THD and a high amplitude error was produced.

In Figure 4(b) is shown the results of the DC voltage when it was set to $260 \mathrm{~V}$ and the THD was 2.95\%. Compare these results to those shown in Figure 4(c) when the DC voltage was set to $400 \mathrm{~V}$ and the THD $4.66 \%$, as well as those shown in Figures 4(d) when the DC voltage was set to and $600 \mathrm{~V}$ and the THD was increased to $6.64 \%$.

It is notable that voltages higher than the designed voltage value of $300 \mathrm{~V}$ produced a higher THD, while the amplitude of the output current was kept constant and tracked the reference current with a small error. On the other hand, for DC voltage values smaller than the designed value, a lower THD with a relatively small amplitude error was produced.

\subsection{Control strategy robustness under variable DC voltages}

Depending on the complexity of the controlled system, the number of calculations can be significant and will limit the minimum sampling time. In the simplest case, predictive current control, the calculation time is small, but in other schemes such as torque and flux control, the calculation time is the parameter which determines the allowed sampling time.

This simulation demonstrated the effectiveness of the proposed control method under conditions of different sampling times; in particular when the sampling time was changed from 25 to $150 \mu$ s at the designed parameters values. Figure 4 shows the output currents for different values of sampling times. It can be observed that the proposed control algorithm has 

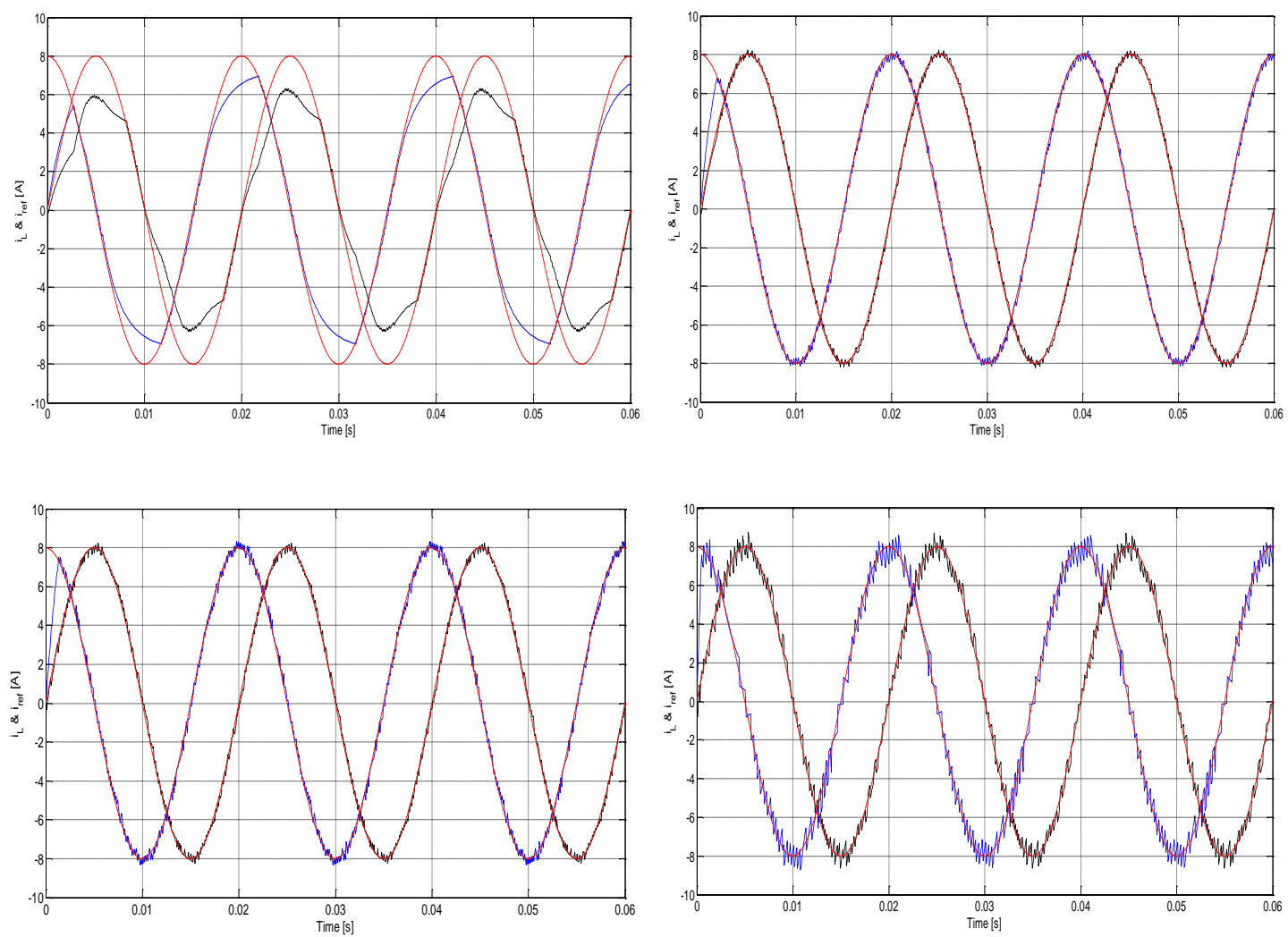

Figure 4: Output currents for different values of DC voltage at Ts $=75 \mu$ s. (a) VDC $=125 \mathrm{~V}$, (b) $\mathrm{VDC}=200 \mathrm{~V}$, (c) VDC $=400 \mathrm{~V}$ and (d) VDC $=600 \mathrm{~V}$.

the ability to follow sinusoidal reference currents despite substantially changing the sampling time from the desired sampling time. These results of the simulation are in Table 3.

In Figure 5 is shown, the results of the output current and output voltages, where current and voltage in one phase of the load are shown in Figure 5(a) and Figure 5(b) for sampling time Ts $=150 \mu$ s and $100 \mu$ s respectively. There is no steady state error in the current but there is a noticeable ripple. This ripple is reduced considerably when a smaller sampling time is used, as shown in Figure 5(c) and Figure 5(d) for a sampling time Ts $=25 \mu$ s and $50 \mu$ s respectively. However, by reducing the sampling time, the switching frequency is increased as can be seen by comparing the load voltages in Figure 5 .

Table 3: THD and output current for variable DC voltages

\begin{tabular}{|c|c|c|c|}
\hline Sampling time $\mathbf{T}_{\mathbf{s}},[\boldsymbol{\mu s}]$ & DC voltage, $[\mathrm{V}]$ & Fund. current at $50 \mathrm{~Hz},[\mathrm{~A}]$ & THD [\%] \\
\hline 25 & 300 & 7.997 & 1.28 \\
\hline 50 & 300 & 7.996 & 2.17 \\
\hline 75 & 300 & 8.009 & 3.48 \\
\hline 100 & 300 & 8.012 & 4.57 \\
\hline 125 & 300 & 7.994 & 5.54 \\
\hline 150 & 300 & 8.018 & 6.77 \\
\hline
\end{tabular}


Almaktoof et al., CEST-2018, AIJR Proceedings 2, pp.223-232, 2018
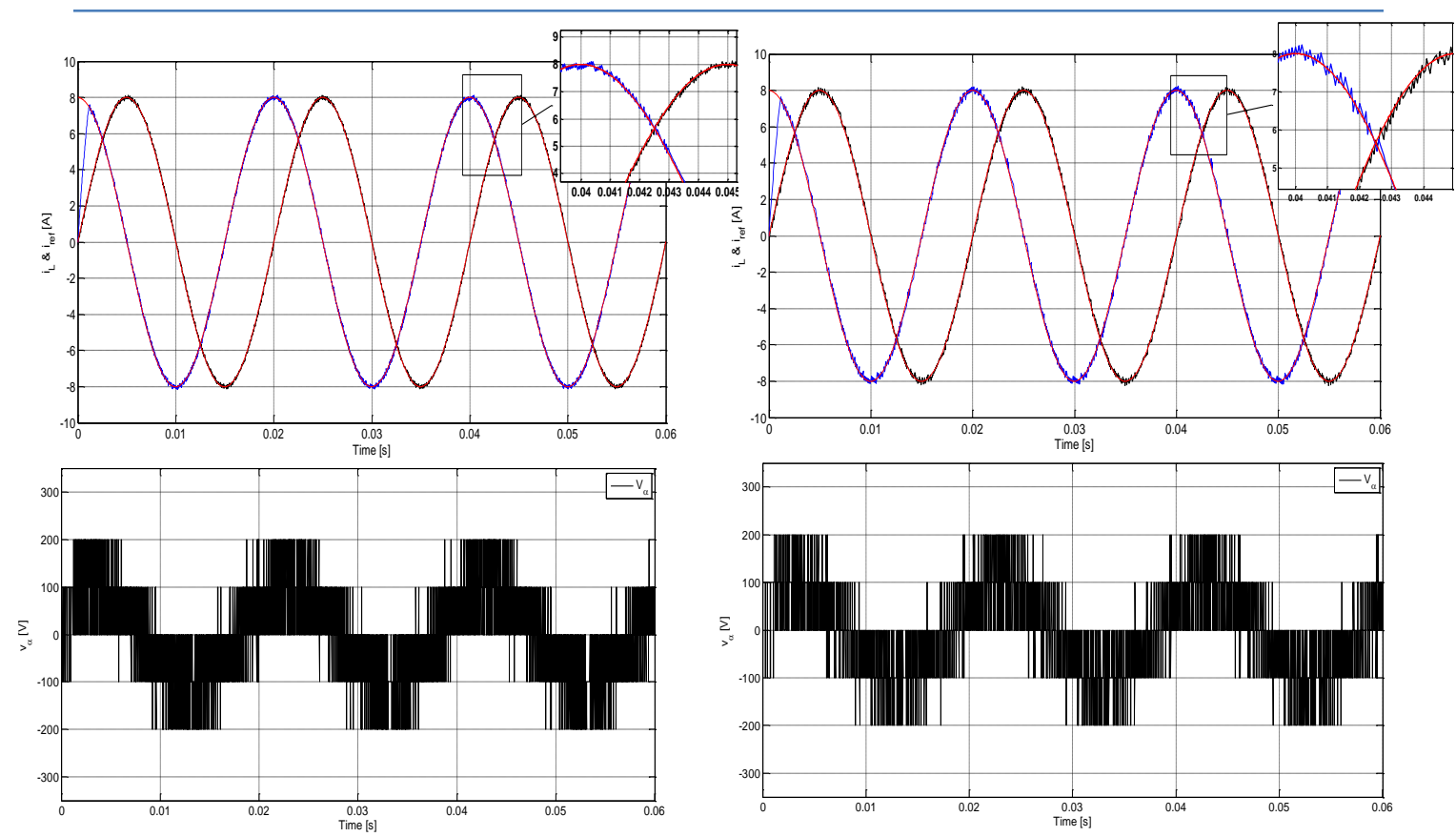

(a)

(b)
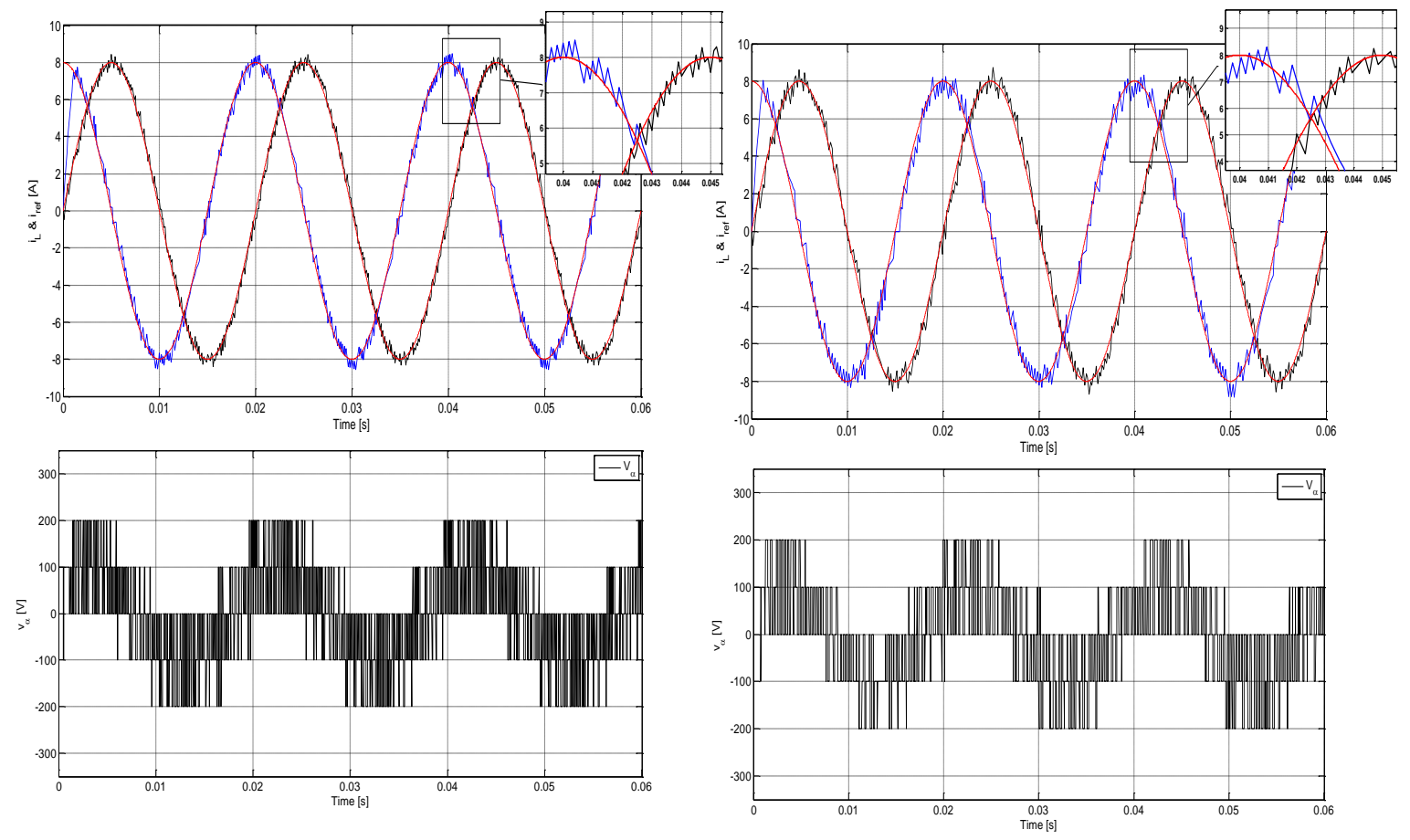

(c)

(d)

Figure 5: Output currents for different values of sampling time $T_{S}$

Proceedings of First Conference for Engineering Sciences and Technology (CEST-2018), vol. 1 231 


\section{Conclusions}

In this paper the MPC strategy for PV system applications has been presented to control the three-phase off-grid inverter. The PV model has been used in this paper to investigate the system performance when power is supplied to RL-load. The proposed control method does not require any kind of linear controller or modulation technique. The FS-MPC algorithm has been evaluated through simulation results. Firstly, the robustness of control strategy under variable DC for three-phase off-grid inverter for PV system application has been done in terms of the THD. Secondly, with different sampling time, the system has been investigated. The simulation results show that the predictive control method has the ability to track sinusoidal reference currents and show excellent tracking behavior with all DC voltage values. Although the theory of MPC was developed in the 1970s, its application in power converters is more recent due to the fast sampling times that are required. The fast microcontrollers available in these days have made it possible to implement the proposed control scheme to three-phase off-grid inverter for PV system application. Sampling time can critically affect the performance of a control system. selecting the best sampling time to execute the entire algorithm is depends on the switching frequency in the load voltages.

\section{References}

[1] Siemens, 2012. Energy Sector 2012, Erlangen (Germany), www.siemens.com/energy [20 May 2018].

[2] A. Nami \& F. Zare. "Multilevel Converters in Renewable Energy Systems, Renewable Energy," T J Hammons (Ed.), ISBN: 978-953-7619-52-7, 2009. InTech, Available from: http://www.intechopen.com/books/renewableenergy/multilevel-converters-in-renewable-energy-systems.

[3] E. J. Bueno, S. Cobreces, F. J. Rodríguez, A. Hernandez, \& F. Espinosa, "Design of a back-to-back NPC converter interface for wind turbines with squirrel-cage induction generator," IEEE Trans. on Energy Conversion, Vol. 23 No.3, 2008. pp.932-45.

[4] L. M. Tolbert \& F. Z. Peng, "Multilevel Converters as a Utility Interface for Renewable Energy Systems," IEEE Power Engineering Society Summer Meeting, Volume 2, 16-20 2000. pp. 1271-1274. Seattle, Washington.

[5] N. Mohan, T. M. Undeland, and W. P. Robbins, "Power Electronics: Converters, Applications and Design," (3rd edition). New York: John Wiley \& Sons. 2003.

[6] R. Kennel and D. Schroeder, "Predictive control strategy for converters," in Proc. the third IFAC Symposium, pp. 415-422, Lausanne, 1983.

[7] A. M. Almaktoof, A. K. Raji and M. T. E. Kahn, "Performance Evaluation and Improvement of an FS-MPC for Two-Level VSI," The International Conference on Electrical and Electronics Engineering, Clean Energy and Green Computing (EEECEGC 2013), United Arab Emirates, pp. 120-126. December 11-13, 2013.

[8] J. Rodríguez and C. Cortés, "Predictive control of Power Converters and Electrical Drives," UK: A Johan Wiley \& Sons, Ltd., 2012.

[9] V. Yaramasu, M. Rivera, B. Wu, \& J. Rodríguez, "Model Predictive Current Control of Two-Level Four-Leg Inverters - Part I: Concept, Algorithm, and Simulation Analysis," IEEE Transactions on Industrial Electronics, vol. 28 no. 7. July 2013, pp. 3459-3468.

[10] H. Abu-Rub, J. Guzinski, Z. Krzeminski, \& H. A. Toliyat. "Predictive current control of voltage source inverters," IEEE Trans. on Ind. Electron, vol. 51 no. 3, 2004. pp. 585-593.

[11] J. Li, F. Zhuo, X. Wang, L. Wang, \& S. Ni, "A grid-connected PV system with power quality improvement based on boost + dual-level fourleg inverter," in Proc. IEEE Int. Power Electron. and Motion Control Conf., Wuhan, China, 2009. pp. 436-440.

[12] R. Vargas, P. Cortés, U. Ammann, J. Rodríguez, \& J. Pontt, "Predictive control of a three-phase neutral-pointclamped inverter," in IEEE Transactions on Industrial Electronics, vol. 54, no. 5, Oct. 2007, pp. 2697-2705. 